\title{
La persona humana en su relación con Dios según la Constitución Pastoral Gaudium et spes
}

En la actualidad vivimos ante una forma de pensamiento y vida que defiende y promueve un concepto de hombre entendido como individuo egoísta y cerrado en sí mismo, en contra de todo lo que signifique darse de forma gratuita, ser responsable y agente activo de lo que ocurre en el mundo. N. Chomsky, describía esta situación del siguiente modo: "Los individuos deben estar solos, enfrentándose al poder centralizado y a los sistemas de información de forma aislada, para que no puedan participar de ningún modo significativo en la administración de asuntos públicos"1.

La Iglesia en medio del mundo, del que no puede huir sin traicionar su propio ser, debe sentir en su interior la responsabilidad de anunciar el proyecto de vida que Dios tiene para el hombre, proyecto que confronta con el impuesto en nuestros días. Hoy en día se es consciente de que el camino de la Iglesia es el hombre, que la teología no puede dejar de lado al hombre concreto y despreocuparse de su vida. De este modo, se nos hace una tarea ineludible volver los ojos al Concilio Vaticano II, por su importancia para la historia de la Iglesia, del cual Juan XXIII llegó a decir que era un "nuevo Pentecostés". Pero especialmente se hace obligado volver a leer sus páginas como punto de partida para hacer una propuesta antropológica hoy en día, siguiendo el ejemplo de Juan Pablo II, que se remite constantemente al Concilio.

Consecuentemente la Gaudium et spes, en la novedad que tuvo para su tiempo y por su carácter pastoral, es un documento conciliar esencial. $\mathrm{Su}$ importancia radica sobre todo en dos aspectos: el primero en su nueva actitud de diálogo con el mundo, y por otro lado, la antropología cristiana, más o 
menos sistemática, y propuesta a lo largo de su páginas. Un modelo antropológico que genera esperanza y vida.

La persona humana es entendida, en el documento conciliar, en su integridad, o sea como ser en sí mismo, autoconsciente y abierto a la relación. Una relación con el Otro, y con los otros en el mundo, o sea en un tiempo y espacio concretos. Se defiende su dignidad, su ser fin y no medio, la labor de construir la familia humana. Y, todo ello, incluido en la misión de la Iglesia de anunciar el Evangelio.

Si analizamos la propuesta antropológica de la Gaudium et spes con detenimiento veremos cómo se plantea como esencial la relación existente con Dios para poder comprender al hombre y su ser como ser relacional. De este modo el siguiente trabajo constará de tres apartados. El primero estará dedicado a profundizar en el porqué de la relación existente entre Dios y el hombre. El hombre se pregunta por sí mismo, por el sentido de su vida, que no puede acabar con la muerte, y la constitución pastoral plantea como su vocación no es otra que la de unirse a Dios, origen y meta del hombre.

El segundo apartado plantea cómo la constitución pastoral, partiendo de la Escritura, describe cuál es la relación del hombre con Dios como criatura, la grandeza del hombre, en cuanto imagen de Dios, y su miseria, al renegar de Él. Y el tercero expone cómo Cristo es el que mediante su encarnación y redención no sólo nos ha redimido, sino que ha instaurado una relación de filiación entre Dios y el hombre.

\section{I.- DIOS AL ENCUENTRO DEL HOMBRE}

\section{1.- LA VOCACIÓN DIVINA DEL HOMBRE}

El hombre es la única criatura que se pregunta sobre sí mismo, quiere dar sentido a su vida, busca la plenitud, y a la vez se encuentra, en medio del mundo, limitado y frágil. La constante referencia ${ }^{2}$ a la plenitud le obliga a verse en la paradoja de verse como una realidad finita que busca el infinito. Ese deseo de Dios dentro del corazón humano responde al propio ser del hombre.

2. "Se trata más bien de una referencia, la cual no se pone por poderío propio, sino que se experimenta como puesta y dispuesta por otro, como fundada en el abismo del misterio inefable". K. RAHNER, Curso fundamental sobre la fe, Barcelona 1979, 62. 


\section{1. Origen de la pregunta por Dios}

De acuerdo con el método inductivo, asumido por la Gaudium et spes, lo primero que hacen los Padres conciliares es plantear una panorámica de la Situación del hombre en el mundo de hoy en la Exposición preliminar. Ésta se encuentra entre dos textos, los números 3a y 10a, llenos de preguntas:

"[El hombre] se formula con frecuencia preguntas angustiosas sobre la evolución presente del mundo, sobre el puesto y la misión del hombre en el universo, sobre el sentido de sus esfuerzos individuales y colectivos, sobre el destino último de las cosas y de la humanidad" (GS 3a).

"¿Qué es el hombre? ¿Cuál es el sentido del dolor, del mal, de la muerte, que, a pesar de tantos progresos hechos, subsisten todavía? ¿Qué valor tienen las victorias logradas a tan caro precio? ¿Qué puede dar el hombre a la sociedad? ¿Qué puede esperar de ella? ¿Qué hay después de esta vida temporal? " (GS 10a).

Las preguntas planteadas reflejan las cuestiones que se hace el hombre en su interior sobre el sentido de su existir en el mundo en que vive, debido a que "la inteligencia del hombre no se ciñe solamente a los fenómenos."(GS 15a). El hombre se pregunta no sólo sobre aquello que le rodea, sino también en su interior se cuestiona sobre sí mismo3.

Lo distintivo del hombre es que está capacitado para ponerse frente a sí como diverso de sus factores integrantes, y ponerse en cuestión: "Todo hombre resulta para sí mismo un problema, percibido con cierta oscuridad"(GS 21d).

La pregunta "¿qué es el hombre?", se concreta en cada uno de nosotros en ésta otra: "¿quien soy yo?", debido a que "la pregunta del hombre acerca de sí mismo se halla en toda cuestión y en todos los actos humanos"4.

La interrogación que se abre sobre el origen, el sentido, y el fin último de la propia existencia es una cuestión ineludible para todo hombre 5 . Las cuestiones "¿por qué comencé a existir y sigo existiendo? "y "¿para qué existo?", son centrales para cada persona humana, y su respuesta mediatiza la forma concreta de vivir.

3. Cf. M. SCHELER, El puesto del hombre en el cosmos, Buenos Aires 1960, 68.

4. J. DE S. LUCAS, El hombre, ¿quién es?, Madrid 1988, 19.

5. Cf. J. Alfaro, De la cuestión del hombre a la cuestión de Dios, Salamanca 1989, 15. 
Estas preguntas necesitan una respuesta ineludible porque "nadie en ciertos momentos, sobre todo en los acontecimientos más importantes de la vida, puede huir del todo el interrogante referido" (GS 21d). De este modo, la pregunta por la existencia de Dios, como sentido de la propia vida, surge para el hombre en los momentos eje de la vida humana, y su respuesta es un grito angustioso desde el fondo del corazón humano.

En este sentido al comentar Juan Pablo II el número 10 de la Gaudium et spes constata que la respuesta que se dé afecta al hombre entero:

"...la respuesta a la pregunta An Deus sit? no es sólo una cuestión que afecte al intelecto; es, al mismo tiempo, una cuestión que abarca toda la existencia humana. Depende de múltiples situaciones en las que el hombre busca el significado y el sentido de la propia existencia. El interrogante sobre la existencia de Dios está íntimamente unido a la finalidad de la existencia humana. No es solamente una cuestión del intelecto, sino también una cuestión de la voluntad del hombre, más aún, es una cuestión del corazón humano (las raisons du coeur de Blas Pascal)"6.

A lo largo de la vida, el hombre experimenta constantemente "múltiples limitaciones" (GS 10a), pero, sin duda, la aparición del dolor y la muerte provocan una profunda reflexión sobre la propia finitud, de hecho "el máximo enigma de la vida humana es la muerte. El hombre sufre con el dolor y con la disolución progresiva del cuerpo." (GS 18a). Sin embargo, el hombre se sabe y se experimenta también superior a las cosas materiales (GS 26b), por su interioridad, o sea por su ser no sólo cuerpo sino cuerpo y espíritu (GS 14b) se encuentra "ilimitado en sus deseos y llamado a una vida superior" (GS 10a). El hombre está sediento "de una vida plena y de una vida libre, digna del hombre" (GS 9c). Esta tensión entre lo que se vive como dado y a lo que se tiende como esperado provoca un conflicto en lo más interno de la persona.

\section{2. EI diálogo de amor entre Dios y el hombre}

La solución al conflicto, al que se aludía, no se encuentra en el mundo material, sino en el hecho de que el hombre está llamado "como hijo, a la

6. JUAN PABLo II, Cruzando el umbral de la esperanza, Barcelona ${ }^{4} 1994,52$. 
unión con Dios y a la participación de su felicidad" (GS 21c), y, por tanto, el "hombre es invitado al diálogo con Dios" (GS 19a).

Es en este diálogo de amor con Dios, donde el hombre se descubre a sí mismo que ha sido creado como el interlocutor válido de Dios, debido a que "...cada Tú singular es una mirada hacia el Tú eterno"7. Tal y como podemos leer en el texto conciliar:

"[El hombre] existe pura y simplemente por el amor de Dios, que lo creo, y por el amor de Dios, que lo conserva. Y sólo puede decir que vive en la plenitud de la verdad cuando reconoce libremente ese amor y se confía por entero a su Creador"(GS 19a) ${ }^{8}$.

El hombre se encuentra a lo largo de toda la vida abierto al diálogo con Dios por iniciativa de Éste, que nos posibilita responder a su llamada ${ }^{9}$, ya que "El nos has amado primero" (1 Jn 4, 10). Ésta afirmación hunde profundamente sus raíces en la Escritura, que como narración de la historia de la salvación ${ }^{10}$, nos muestra cómo es Dios quien llama a la vida: "hagamos al hombre a nuestra imagen, según nuestra propia semejanza" (Gen 1,26); sostiene la existencia y por ello se puede decir "Señor, por tí vive mi corazón, vive mi espíritu" (Is 38,16); y por la resurrección de Cristo preguntar: "¿Dónde está muerte, tu victoria?" (1 Cor 15,55$)$.

\section{3. El hombre llamado a la unión con Dios}

La constitución pastoral, refiriéndose a S. Agustín, nos señala que "lo único que puede llenar el corazón del hombre es aquello de «nos hiciste, Señor, para tí, y nuestro corazón está inquieto hasta que descanse en tí»"(GS 21g) 11.

7. M. Buber, Yo y Tu, Madrid 1996, 43.

8. Según J. L. Lorda "no se puede dejar de notar la impronta personalista de este texto donde se interpreta toda la vida del hombre como un diálogo con Dios que se inicia en el mismo momento en que Dios quiere llamar al ser a un hombre..." J. L. LorDA, Antropología. Del concilio Vaticano II a Juan Pablo II, Madrid 1996, 83. II/ 1,60 .

9. Cf. H. U. VON BALTHASAR, "El camino de acceso a la realidad de Dios", en Mys. Sal.,

10. Recordemos las palabras de PABLO VI: "La historia de la salvación narra precisamente este largo y variado diálogo, que parte de Dios y entabla con el hombre múltiple y admirable conversación". Ecclesiam Suam, 64.

11. Recordemos cómo estas palabras se encuentran en un contexto de alabanza a Dios por su amor al hombre. S. Agustín, Confesiones, I, 1, en PL 32, 661.; trad. castellana en BAC II, Madrid 1946, 325. 
El hombre encuentra respuesta a las preguntas sobre el sentido de la vida en Dios. Dios es el Principio y el Fin último, de donde procede el hombre y a lo que tiende ${ }^{12}$. El deseo de Dios, puesto por el mismo Dios en el hombre, expresado en el texto de S. Agustín, es imprescindible para entender la relación existente entre Dios y el hombre, que se expresa a lo largo de la constitución pastoral.

El deseo de Dios, de lo trascendente, incluido dentro de la Gaudium et spes, es un fruto recogido de la polémica del "sobrenatural" planteada desde la tradición patrística, y preocupación de grandes teólogos como Sto. Tomás, Cayetano,... Tras la publicación de la encíclica de Pio XII Humani generis (1950) se hicieron importantes aportaciones ${ }^{13}$ a la polémica del "sobrenatural", tales como la de H. de Lubac (con una importante influencia en el concilio), K. Rahner, J. Alfaro, o H. U. Von Balthasar.

La constitución pastoral trata el tema pero no recoge los términos de la polémica, "natural" y "sobrenatural", para no caer en una unilateralidad extrinsecista o inmanentista, y recurre a expresiones evangélicas que reflejan mejor la totalidad de la vida humana ${ }^{14}$.

Para la Gaudium et spes está claro que "Dios ha llamado y llama al hombre a adherirse a El con la total plenitud de su ser en la perpetua comunión de la incorruptible vida divina"(GS 18b). En la llamada está la promesa de una vida plena, una promesa que es Dios mismo, que nos responde, en su darse al hombre, a esos interrogantes por el sentido de la vida. La angustia que provoca la muerte, como el fin, se torna en esperanza en el Fin, porque "...el hombre ha sido creado por Dios para un destino feliz situado más allá de las fronteras de la miseria terrestre" (GS 18b). En definitiva, podemos afirmar con el concilio que "...la vocación suprema del hombre en realidad es una sola, es decir, la divina" (GS 22e). El deseo del hombre de "ser como Dios" 15 , se cumple sólo si a Éste se le reconoce como Fin último, y sentido de nuestra existencia.

12. Cf. GS 13a.

13. Un resumen y crítica muy valiosos del pensamiento de H. de Lubac, K. Rahner, y J. Alfaro, que sirven como base para la aportación del autor, pueden verse en L.F. LADARIA, Introducción a la antropología teológica, Estella (Navarra) 1993, 19-30.

14. Cf. M. D. Chenu, "Misión de la Iglesia en el mundo contemporáneo", en G. BARAUnA (dir.), la Iglesia en el mundo de hoy. Estudios y comentarios a la Constitución «Gaudium et spes» (Esquema XIII), Madrid 1967, 390.

15. Nos referimos al deseo que aparece ya en el libro del Génesis (Gen 3,5). 


\section{2.- DIMENSIÓN HISTÓRICA DEL ENCUENTRO CON DIOS}

La constitución pastoral sitúa el encuentro ${ }^{16}$ entre la persona humana y Dios "en el mundo de hoy". Es el título mismo de la constitución pastoral el que nos da la clave. La relación se concreta en el mundo "teatro de la historia humana, con sus afanes, fracasos y victorias" (GS 2) ${ }^{17}$, a partir de los acontecimientos y características propias de ese mundo, y en un tiempo histórico concreto.

La conciencia de la historicidad del ser humano "ha penetrado en la civilización contemporánea y se ha demostrado indispensable para comprender el fenómeno humano" 18 gracias sobre todo al personalismo ${ }^{19}$, y otras corrientes de pensamiento que influyeron sobre los teólogos más importantes de este siglo, a los cuáles debe mucho el concilio ${ }^{20}$. La historicidad del hombre conlleva necesariamente a que éste sea llamado por Dios en la historia.

\section{1. La Escritura}

\section{1. 1. Antiguo testamento 21}

En el Antiguo Testamento vemos como Yhavé se revela "personalmente" 22 a su pueblo a lo largo de la historia de la salvación. Crea al hombre a su

16. Al escoger la categoría de "encuentro" para describir la relación entre la persona humana y Dios se plantea una relación interpersonal de hecho "el encuentro es un acontecimiento tan raro como feliz que sucede en la relación entre las personas" J. MARTín VELASCO, El encuentro con Dios. Una interpretación personalista de la religión, Madrid 1976, 23.

17. "...la Iglesia, tratando de definirse, «busca al mundo» (cardenal Montini) para definirse constitucionalmente en el mundo, en aquel punto en el que el rodar de la historia es un factor esencial de esta relación" M.-D. CHENU, "Los signos de los tiempos. Reflexión teológica", en Y. M.-J. Congar - M. Peuchmaurd (dirs.), Vaticano II. La Iglesia en el mundo de hoy. Constitución pastoral «Gaudium et spes», II, Madrid 1970, 254.

18. M. FLICK- Z. AlSZEGHY, Antropología teológica, Salamanca 1977, 114.

19. $\mathrm{Ph}$. Delhaye ha señalado la influencia de los pensadores personalistas en los redactores de Gaudium et spes, en concreto "el personalismo cristiano de Lacroix y Mounier en el cual Mons. Haubtman se ha inspirado al redactar la primera parte de la Gaudium et spes". Ph. DelHAYe, "Personalismo y trascendencia en el actuar moral y social", en Scripta Theologica $12 / 1(1980) 13$.

20. Sobre la importancia del trabajo de los teólogos en el concilio puede verse el trabajo de K. H. NeufELD, Obispos y teólogos al servicio del concilio Vaticano II.en R. LATORELLE (dir.), Vaticano II. Balance y perspectivas, Salamanca 1989, 65-84.

21. Sobre Dios inmanente en la historia, aunque sólo en los libros del Pentateuco, se puede consultar la obra de B. ANDRADE, Encuentro con Dios en la historia. Estudio de la concepción de Dios en el Pentateuco, Salamanca 1985, 141-214.

22. En la relación entre Israel y Dios aparece un carácter personal, "personal no funda- 
imagen, le da un nombre, y pone a su disposición toda la creación como rey de la misma. Hace una alianza con Israel en el Sinaí, le eligió y "denominó pueblo suyo (Ex. 3, 7-12)" (GS 32 a). La iniciativa de Dios para salir al encuentro del pueblo elegido ${ }^{23}$ caracteriza la relación divino-humana. Con palabras de H. U. Von Balthasar:

"El Dios de Israel pone, en su primera acción salvífica histórica, el fundamento para la unidad de la idea de Dios que el hombre intenta inútilmente llegar a concebir. Dios se muestra así como el poderoso y el bueno, el «que acude a sacar» $($ Dt 4,34$)$ y que «elige» (Dt 7,6) un pueblo. Dios ejecuta y establece este hecho mediante una llamada y una salvación selectiva (de manos de los egipcios), que él ejecuta ante todo como sujeto activo y como compañero. Israel no puede aducir méritos ni prerrogativas peculiares (Dt 7,7; 8,17). Es lo que es porque ha sido llamado el «pueblo para Yhavé». El fundamento de su elección es un amor sin fundamento por su parte (Dt 7,7.9), al que sólo cabe responder con un amor tal, ilimitado (Dt 6,5) (...) El carácter excepcional de este acontecimiento de un amor total y absolutamente incondicionado, que, en cuanto tal, indica un ser omnipotente (...), demuestra que el ser que elige es también único y excepcional (Is 43, 210-12): su amor absoluto demuestra la absolutuidad de su ser" 24 .

\subsubsection{Nuevo testamento}

El Hijo es el "mediador y plenitud de toda la revelación"(DV 2), "imagen de Dios invisible"(GS 10b), "la clave, el centro y el fin de toda la historia humana" (GS 10b), que nos ha enviado al Espíritu Santo para que sea nuestro guía en el "peregrinar hacia el reino del Padre" (GS 1).

La Encarnación del Verbo se produce en un tiempo histórico concreto, en tiempos de Herodes, el Grande (Mt 2,1), de Cesar Augusto (Lc. 2, 1), y siendo gobernador de Siria Cirino (Lc. 2, 2); y su muerte aconteció "bajo

mentalmente porque atribuya al Dios reconocido las propiedades de la persona, sino porque tiene lugar como una invocación suscitada por una previa llamada". J. MARTíN VELASCO, o.c., 53.

23. En GS 48b al referirse al matrimonio y a la familia se puede leer como "...Dios antiguamente se adelantó a unirse a su pueblo por una alianza de amor y fidelidad" y se citan a pie de página los siguientes pasajes del Antiguo Testamento: Os 2; Jer 3, 6-13; Ez 16 y 23; Is 54.

24. H. U. von BALTHASAR, "El camino de acceso a la realidad de Dios", en o.c., 51. 
Poncio Pilato"25 (Mc 15,1-15). El misterio de la encarnación, muerte y resurrección de Jesús, nos muestran a Dios que asume la naturaleza humana, y se une al hombre.

\section{2. Los signos de los tiempos}

Como hemos visto someramente en la Escritura, la imagen de un Dios totalmente Otro y distante, la imagen deísta de un Dios que pone el mundo en marcha y después se despreocupa de él, no es válida dentro del cristianismo, porque " el Dios metacósmico de la creación se revela como el Dios intrahistórico de la salvación. El Dios de la alianza de Israel es también el Dios de las naciones, el Dios de la creación y de la esperanza cristiana" 26.

Con esta perspectiva de la cercanía de Dios interesará analizar, aunque siempre en un nivel diferente al de la Escritura, un concepto como el de "signos de los tiempos", y descubrir su significado dentro de la constitución pastoral.

\section{2.1. Origen y sentido del término "signos de los tiempos"27}

El término "signos de los tiempos" se introduce en su sentido tópico por Juan XXIII en la bula por la que se convocó el concilio Vaticano II, Humanae salutis, del 25 de diciembre de 1961, refiriéndose a Mt 16, 3 28. También se encuentra implícito el término "signos de los tiempos" en la Encíclica Pacem in terris, publicada el 11 de abril de 1963, dado que en ella se analizan los rasgos característicos de la época reconocidos como signos de la presencia de Dios y de la Iglesia en el mundo de aquellos momentos. Por su parte Pablo VI

25. "...lo auténtico del mensaje del cristianismo está precisamente en la afirmación de que este Jesús, muerto bajo Poncio Pilato, no puede ser otro que el Cristo, el Hijo de Dios, el salvador absoluto. De este suceso histórico depende la salvación de todos los tiempos y mi salvación, que está fundada en este suceso histórico y singular." Ib., 275.

26. F.-A. PASTOR, "El hombre y su búsqueda de Dios", en R. LATOurelle (ed.), o.c., 702.

27. Para un análisis más detallado de cómo se llegó a introducir el término "signos de los tiempos" en la Gaudium et spes, puede verse el artículo de M.-D. CHENU, "Los signos de los tiempos. Una reflexión teológica", en Y. M.-J. Congar-M. Peuchmaurd (dirs.), o.c., II, 254-259.

28. Cf. JUAN XXIII, Humanae salutis, 6-I- 1962, en AAS. 54 (1962) 6. 
en su primera Encíclica, Ecclesiam suam, del 6 de agosto de 1964, introdujo el término "signos de los tiempos", en el número 46.

Evidentemente, estas aportaciones pontificias, se tuvieron en cuenta en la elaboración de la Gaudium et spes. De hecho, la Exposición preliminar es un análisis de la "Situación del hombre en el mundo de hoy", apareciendo el término "signos de los tiempos" explícitamente en el número 4, y de forma implícita en el número 11. Y a lo largo de toda la Exposición preliminar se describe la situación histórica dentro de la que se celebra el Concilio. Numerosos acontecimientos llamaban la atención tales como las esperanzas, temores y paradojas del mundo en el que vivían ${ }^{29}$; los cambios profundos y rápidos producidos en la sociedad, la moral, la familia y a nivel psicológico; los desequilibrios y contradicciones en el orden teórico y práctico de la existencia humana; y las aspiraciones más universales de la humanidad.

Este tema del discernimiento de los signos de los tiempos, o de "la presencia de Dios en la historia "30, también se planteó en el capítulo IV de la primera parte que trata sobre la "Ayuda que la Iglesia trata de aportar a la sociedad humana". El discernir los signos de los tiempos será una tarea que repercutirá en el pensamiento teológico posterior a la hora de plantearse los problemas de actualidad.

\section{2. 2. Contenido y significado}

El término "signos de los tiempos" puede definirse sociológicamente como aquellos "fenómenos que, a causa de su generalización y gran frecuencia, caracterizan una época, y a través de los cuales se expresan las necesidades y las aspiraciones de la humanidad presente" 31 . Sin embargo, y aún admitiendo esta definición, su contenido y profundidad es mayor para la Iglesia, ya que los "interpreta a la luz del Evangelio" (GS 4a), y procura discernir en ellos la presencia actual de Dios o sus planes ${ }^{32}$, ya que cree que el Espíritu de Dios, guía el curso de los tiempos, y no es ajeno a la evolución de los mismos.

29. Cf. GS 4-9.

30. M.-D. Chenu, "Los signos de los tiempos. Una reflexión teológica", en Y. M.-J. CONGAR-M.PEUCHMAURD (dirs.), o.c.,II, 258.

31. M.-D. ChEnU, "Los signos de los tiempos. Reflexión teológica", en Y. M.-J. CongARM. Peuchmaurd (dirs.), o.c.,II, 257.

32. Cf. GS $11 \mathrm{a} ; 26 \mathrm{c}$ 
Sin duda, "...con sus tendencias, corrientes y acontecimientos relevantes, el mundo es un espejo donde se refleja la voluntad de Dios en la historia. Una voluntad percibida por quienes tienen ojos para ver el sentido oculto de lo que está pasando"33.

Con todo ello, el concilio se propuso juzgar bajo la luz del evangelio los valores que se disfrutaban en su época "de máxima consideración y enlazarlos de nuevo con su fuente divina. Estos valores, por proceder de la inteligencia que Dios ha dado al hombre, poseen una bondad extraordinaria; pero, a causa de la corrupción del corazón humano, sufren con frecuencia desviaciones contrarias a su debida ordenación. Por ello necesitan purificación" (GS $11 b)^{34}$. A pesar de todo, en la época del Concilio aparecen signos claros en los que puede leerse el encuentro de Dios con el hombre. Entre los más claros se encuentran el respeto a la proclamación de la dignidad de la persona como valor absoluto y universal, el reconocimiento de la libertad humana como derecho inviolable, el sentido de solidaridad entre todos los hombres como exigencia ética ineludible, la atención a los marginados, el rechazo de toda suerte de discriminación como deber de todos, etc...

\section{LA FE COMO RESPUESTA PLENA A LA PREGUNTA HUMANA}

La relación entre Dios y el hombre se plantea, de este modo, como un "salir de" y un "ir hacia". Dios al hacerse hombre, en su infinito amor, se revela definitivamente en su Hijo, que nos manifiesta con sus palabras y sus obras, en su muerte y resurrección, el amor del Padre en el Espíritu Santo. La razón que busca la verdad necesita de la fe en Jesús para que el hombre pueda acceder al misterio íntimo de Dios.

Brevemente describiremos el papel que juega la fe dentro de la constitución pastoral. Lo primero que se advierte es que la fe tiene una función muy precisa para la Gaudium et spes. Ayuda a que el hombre ordene la vida a su Fín último, a Dios, porque "la fe todo lo ilumina con nueva luz y manifiesta el plan divino sobre la entera vocación del hombre" (GS 11a). Esa nueva luz, que ilumina y manifiesta el plan de amor de Dios con el hombre, es fruto del

33. J. DE S. LuCAS, "Diálogo con el mundo y signos de los tiempos", en Misión Abierta 90/1 (1990) 38.

34. Cf. M.-D. Chenu, "Los signos de los tiempos. Una reflexión teológica", en Y. M.-J. Congar-M. Peuchmaurd (dirs.), o.c., II, 267. 
amor divino al hombre, es un don de Dios ${ }^{35}$. Pero este don no elimina la libertad humana, sino que es dinámico porque a la acción primera de la gracia divina debe corresponder la persona libremente, mejor o peor. La fe no es sólo un asentimiento intelectual a unas verdades, sino un asentimiento de todo el ser y existir, que transforma la persona. Es un compromiso para con Dios y el prójimo que implica seguimiento. Según $H$. de Lubac: "Esta fe que está en nosotros, que nos impregna y nos posee, no es cosa nuestra (...). Es una relación esencialmente móvil con una realidad que nos penetra y nos domina, que nos envuelve, nos escudriña y nos juzga al mismo tiempo que nos ilumina y nos vivifica. Realidad de la que nosotros vivimos siempre más o menos mal, en nuestra misma inteligencia, y a la que incluso con nuestra mejor voluntad, somos siempre más o menos infieles" 36 .

La fe se presenta, de este modo, en la constitución pastoral como "la respuesta total de Dios a la pregunta total del hombre"37. A las preguntas más angustiosas hechas por el hombre la fe es capaz de darlas respuesta, porque "la fe cristiana enseña que la muerte corporal que entró en la historia a consecuencia del pecado, será vencida cuando el omnipotente y misericordioso Salvador restituya al hombre en la salvación perdida por el pecado" (GS 18b). La fe marca al hombre la pauta de su destino, que no es otro que el encuentro definitivo con Dios allende la vida terrena.

\section{II.- LA PERSONA HUMANA CREADA A IMAGEN DE DIOS}

\section{LA GRANDEZA DEL HOMBRE}

\section{1. El hombre imagen de Dios}

El hombre considerado como creatura es preámbulo indispensable que lo ubica en la perspectiva del mundo creado, y es la concepción fundamental

35. Cf. GS 15d. Esto también se afirma en la constitución Dei Verbum: "Para dar esta respuesta de la fe es necesaria la gracia de Dios, que se adelanta y nos ayuda, junto con el auxilio interior del Espíritu Santo, que mueve el corazón, lo dirige a Dios, abre los ojos del espíritu y concede «a todos gusto en aceptar y creer la verdad»". (DV 5).

36. H. DE LubaC, Ateísmo y sentido del hombre, Madrid 1969, 79.

37. A. MANARANCHE, El hombre en su universo, Salamanca 1968, 85 . 
para la comprensión cristiana del hombre ${ }^{38}$, dependiente de Dios como de su primer principio y último fin. Este aspecto, "aunque fundamental para la antropología teológica, no es sin embargo su elemento específico, en efecto, la condición creada es un atributo de todo el universo finito, en cuya cima se encuentra el hombre: la revelación habla del hombre «creado a imagen de Dios»"39.

A la pregunta por el hombre, la constitución pastoral responde desde la Escritura: "el hombre ha sido creado «a imagen de Dios»" (GS 12)40. Este concepto de "imagen de Dios", según Ph. Delhaye, es muy importante en la elaboración del texto conciliar, ya que "la Subcomisión (entre otros monseñor Garrone, los Reverendos Padres Congar y Danielou) encontró el hilo de Ariadna explotando el tema bíblico-patrístico del hombre imagen de Dios ${ }^{41}$ ".

El mismo autor comenta como este tema de la imagen de Dios en la Escritura se vio enriquecido en el texto conciliar por las aportaciones de los Padres conciliares, y que la presencia de patrólogos en esta Subcomisión de trabajo provocó que se planteara el tema del hombre como "imagen de Dios" en su sentido pleno ${ }^{42}$. Por su parte, J. Cordero nos recuerda la influencia de la Pacem in terris, para la asunción del concepto, e indica como la encíclica parte de la concepción del hombre como imagen de Dios al citar Gen 1, 26: "Dios creó al hombre a su imagen y semejanza"(PT 3$)^{43}$.

La concepción del hombre "creado a imagen de Dios" es clave en la constitución pastoral ${ }^{44}$, hunde sus raíces en la Escritura y la Tradición, y proclama la dignidad y grandeza del hombre. Así lo afirmó Juan Pablo II en su discurso al CELAM el 28 de enero de 1979 en Mexico. En esta ocasión afirmó el pontífice cómo "la Iglesia posee, gracias al Evangelio la verdad sobre el

38. "La creaturidad del hombre no es un «primer piso» que pueda visitarse independientemente de los otros tres [imagen divina, pecado, gracia]. Creaturidad e imagen de Dios forman, en el hombre, una unidad indisoluble, donde es imposible aislar con precisión lo que pertenece a cada una de esas denominaciones. Y la creaturidad que conocemos es una creaturidad empecatada y agraciada..." . J. I. GonZÁlez Faus, Proyecto de hermano. Visión creyente del hombre, Santander 1987, 19.

39. M. Flick y Z. AlsZEGHY, Antropología teológica, ed.c., 95.

40. "Centrada en la concepción del hombre como imagen de Dios, la Constitición conciliar esboza una antropología cristiana completa..." J. CORDERO, "El principio antropológico en la Constitución «Gaudium et Spes» del Vaticano II", en Ciencia Tomista 96 (1969) 619.

41. Ph. Delhaye, "Dignidad de la persona humana", en G. Barauna (dir.), o.c., 304.

42. 2 Cf. Ib., 304.

43. Cf. J. Cordero, a.c., 620.

44. Cf. M. Flick y Z. Alszehgy, Antropología teológica, ed.c., 104. 
hombre. Esta verdad está centrada en una antropología que la Iglesia no deja de profundizar y comunicar. La afirmación primordial de esta antropología es la del hombre como imagen de Dios, irreducible a una mera porción de la naturaleza o a un elemento anónimo de la ciudad humana"45.

Los textos de la Escritura que se citan a pie de página para justificar la afirmación del hombre "creado a imagen de Dios" propuesta en el número 12 del texto conciliar, son Gen 1,26 y Sab 2,23. El primer texto nos sitúa ante la especial dignidad del hombre como imagen de Dios y la absoluta trascendencia de Éste ${ }^{46}$. El segundo pone de relieve la relación existente entre el tema de la imagen de Dios y la inmortalidad 47 .

Optar por definir al hombre desde la Escritura, antes que desarrollar sus elementos constitutivos, indica el abandono de los esquemas neoescolásticos por una noción bíblica -dinámica y dialogal- del hombre, que los Padres conciliares tuvieron muy en cuenta en sus reflexiones ${ }^{48}$. En el texto conciliar el hombre a imagen de Dios supone:

a) la "capacidad para conocer y amar a su Creador" (GS 12c),

b) ser "constituido señor de la entera creación visible para gobernarla y usarla glorificando a Dios" (GS 12c),

c) y el hecho de que "Dios no creó al hombre en solitario (...) y no puede vivir ni desplegar sus cualidades sin relacionarse con los demás" (GS 12d).

Esta relación del hombre con Dios, el mundo y los otros hombres no puede olvidar que "...el Concilio lo hace depender todo de la relación con Dios: de tal modo que si está amenazada, acometida o negada, las otras dos se encuentran en entredicho" 49 , así la relación con Dios es el fundamento de las otras dos. Por otra parte, el Salmo 8, 5-7, citado en el número 12, nos indica cómo el hombre ocupa un puesto especial en la creación, ya que ha sido

45. JuAn PABLo II, Discurso al CELAM,28-1-1979, en AAS LXXI (1979) 195-196.

46. Cf. W. SEIBEL, "El hombre, imagen sobrenatural de Dios. Su estado original", en $M y s$. Sal, II/2, 902.

47. Cf. M. Flick y Z. Alszehgy, Antropología teológica, ed.c., 127-128.

48. Cf. J. MourouX, "Sobre la dignidad de la persona humana", en Y. M.-J. ConGAR - M. Peuchmaurd (dirs.),o.c.,II, 289.

49. Ib., 291. 
creado para existir en relación con Dios, concibiendo así la vida del hombre como un contacto misterioso del hombre con Dios.

En este número 12 se puede apreciar la influencia del pensamiento de Sto. Tomás sobre "el hombre imagen de Dios". Sto. Tomás afirma que el alma del hombre es imagen de la Trinidad, ya que es toda la Trinidad la que crea al hombre a imagen suya ${ }^{50}$. En este sentido el hombre puede imitar a Dios en lo que es propio de Éste, o sea conocerse y amarse. Así la imagen de Dios se ve en conexión con la capacidad de relacionarse con Dios pudiendo conocerle y amarle 51 .

El final del número 12 acaba citando un juicio de Dios, el cual nos hace reflexionar sobre la excelsa dignidad del hombre, que no sólo es creado a imagen de Dios sino bendecido explícitamente: "miró cuanto había hecho, y lo juzgó muy bueno (Gen 1,31)" (GS 12e). En posteriores números se trata la imagen en su constitución unitaria (GS 14), y las tres propiedades esenciales de la imagen (GS 15-17); éstas se tratarán no de forma exhaustiva sino exclusivamente en su relación con el tema de esta primera parte del trabajo.

\section{2. La unidad estructural del hombre y sus propiedades esenciales}

\section{2. 1. El hombre es uno cuerpo y alma}

El número 14 del texto conciliar constituye la cima de una evolución en el pensamiento de la Iglesia, en la que se pasa de la afirmación de que «el hombre tiene cuerpo y alma» a ésta otra: «el hombre es en cuerpo y alma» 52 . Así se subraya como "en la unidad de cuerpo y alma, el hombre, por su misma condición corporal, es una síntesis del universo, el cual alcanza por medio del

50. Cf. Sum. Theol. I, 93, 5 .

51. Cf. Ib., I, q. 93, a.4.

52. "La trayectoria seguida por las declaraciones del magisterio representa una progresión creciente hacia la afirmación de la unidad del hombre, a través de tres grandes hitos: a)los textos magisteriales hasta Letrán IV inclusive, hablan de una naturaleza humana que consta de (o está constituida por) alma y cuerpo; b) Vienne da una paso más cuando enseña que el alma y cuerpo se unen sustancialmente; pero el sujeto de su aserto es todavía el alma (anima forma corporis); c)en fin, el Vaticano II (GS 14) asevera categóricamente que «el hombre es uno en cuerpo y alma» (corpore et anima unus)." J. L. RUIZ DE LA PEÑA, Imagen de Dios, Santander 1988, 129. 
hombre su más alta cima y alza la voz para la libre alabanza del Creador" (GS $14 a)^{53}$.

La afirmación es clara para el Concilio: "el hombre es cuerpo y alma"54. El hombre es cuerpo, es decir, existe como tal en el espacio y en el tiempo, pero es a la vez alma, porque trasciende la finitud del mundo, y se encuentra abierto a Dios como interlocutor válido.

El cuerpo adquiere la importancia que había perdido, es parte integrante y básica del hombre, y "éste queda asumido a la condición de imagen de Dios que es definidora del ser del hombre. El cuerpo humano y la actuación humana bajo las condiciones que de él se dimanan, tendrán el designio de ser un reflejo y una proclamación de la gloria del Creador..." 55.

En esa unidad del hombre se explican dos aspectos claves de la relación con Dios: el hecho de que Dios se manifieste en la historia, en lo espacio-temporal propio del ser finito y limitado del ser "cuerpo animado" del hombre, y por otro el hecho de que el hombre en su interior pueda encontrar a Dios por ser "alma corporeizada". Otro aspecto interesante es la reiteración que se hace del hombre como centro de la creación de Dios, la cita de éste número 14 al cántico de Daniel (Dan 3,57-90), sitúa al hombre no sólo como cima de la creación, sino también en su labor de alabar al Creador junto con el resto de la Creación, expresando ambos aspectos "lo humano como capacidad de referencia a lo divino" 56 .

\section{2. 2. Propiedades esenciales del hombre como imagen de Dios}

Los números 15, 16 y 17 se ocupan de describir las tres propiedades esenciales del hombre como imagen de Dios: la inteligencia, la conciencia y la libertad ${ }^{57}$.

53. Dejamos de lado, aunque su importancia es notable, el hecho de que el concilio entienda al hombre como "síntesis del universo material". Se aprecia la influencia del pensamiento del $\mathrm{P}$. Teilhard de Chardin en esta concepción del hombre. Nos remitimos para una mayor profundización al estudio hecho por J. DE S. LuCAS, "Aportación del P. Teilhard de Chardin al concilio Vaticano II", en Burgense 23/1 (1982) 203-205.

54. Para un estudio detallado del tema nos remitimos a J. L. RuIz DE LA PEÑA, Imagen de Dios, ed.c., 129-151.

55. J. CORDERO, a.c.,623.

56. J. L. RuIZ DE LA PeÑa, Imagen de Dios, ed.c., 140.

57. Cada una de estas propiedades del hombre como imagen de Dios requerirían un estudio profundo y amplio, que debido a la entidad del presente trabajo no podemos llevar a 


\section{2. 1. La inteligencia}

El número 15 de la constitución pastoral expone cómo el hombre "participante de la luz de la inteligencia divina, (...) es superior al universo material" (GS 15a). Se repite, por tanto, la afirmación de la supremacía del hombre, y se subraya la importancia de la inteligencia para que el hombre pueda conocer a Dios, ya que gracias a la inteligencia el hombre de todos los tiempos siempre "ha buscado y ha encontrado una verdad más profunda" (GS $15 a)^{58}$. Según J. Mouroux en este texto se defiende que" la inteligencia es uno de los aspectos más altos de la imagen divina y que, en su primer origen, es un fulgor divino en el corazón del ser humano. Este poder para conocer los seres existentes creados, el mundo espiritual y a Dios mismo, es precisamente lo que fundamenta la trascendencia natural del espíritu con relación al cosmos" 59 .

Sin embargo, esta inteligencia debe perfeccionarse por la sabiduría gracias a la cual "el hombre se alza por medio de lo visible hacia lo invisible"(GS 15b). De hecho, "con el don del Espíritu Santo, el hombre llega por la fe a contemplar y saborear el misterio del plan divino" (GS $15 \mathrm{~d})^{60}$.

\section{2. 2. La conciencia}

En el número 16 aparece la conciencia como el lugar en el que el hombre se encuentra "a solas con Dios", es el "sagrario del hombre". Es, por consiguiente, un tipo de relación con Dios fundamental y esencialmente humana, que se realiza activa y pasivamente a través de la escucha y la obediencia.

cabo. Por tanto, nos limitaremos sólo a señalar algunos puntos interesantes para el tema del que se ocupa este trabajo.

58. Se aprecia la influencia del capítulo cuarto de la constitución dogmática sobre la fe católica del Vaticano I, Dei Filius, sobre el puesto de la razón natural respecto al conocimiento de Dios. Denzinger, 1795-1796.

59. J. Mouroux, "Sobre la dignidad de la persona humana", en Y. M.-J. CONGAR - M. Peuchmaurd (dirs.),o.c., II, 295.

60. Sobre la relación entre la fe y razón nos remitimos a la última encíclica de JUAN PABlo II, Fides et ratio, sobre todo los cuatro primeros capítulos de la misma. FR 7-48. 


\section{2.3. La libertad}

El número 17 aborda la libertad como "...signo eminente de la imagen divina en el hombre" (GS 17). Dios ha creado un hombre libre, que toma sus propias decisiones y que con el "uso de la libertad" puede orientar todo su ser hacia el bien. El ser del hombre pide de por sí "que el hombre actúe según su conciencia y libre elección, movido e inducido por convicción interna personal"(GS 17)61. La libertad del hombre persigue el que éste "busque espontáneamente a su Creador y, adhiriéndose a éste, alcance la plena y bienaventurada perfección" (GS 17). El pecado ha dañado la libertad humana, pero Dios no deja abandonado al hombre a su suerte, y para apoyar la libertad humana sale a su encuentro. De este modo "La libertad humana, herida por el pecado, para dar la máxima eficacia a esta ordenación a Dios, ha de apoyarse necesariamente en la gracia de Dios" (GS 17).

Con esto se puede concluir con J. Mouroux lo siguiente:

"La libertad implica una relación directa con Dios; es, por tanto, una capacidad orientada hacia la búsqueda de Dios, y el perfeccionamiento de sí mismo mediante la unión con Él. De ninguna manera puede ser el poder de hacer, según el propio capricho, «cualquier cosa, incluso el mal»" 62 .

\section{LA MISERIA DEL HOMBRE}

La relación con Dios a la que se ve abocado el hombre, como imagen suya, tal y como nos revela la Escritura, vemos que está empañada desde los comienzos. Pero también apreciamos que en nuestro propio interior, en la sociedad y en el mundo en el que vivimos, notamos que la armonía no existe, y que vivimos en un constante estado de contradicción.

61. Ph. Delhaye comentando este punto afirma que "esta verdadera libertad es un elemento de la imagen de Dios en el hombre y está necesariamente orientada hacia Dios. Ella implica que el hombre se libera de las pasiones que lo esclavizan, tiende por sí mismo hacia su fin supremo y acepta los medios necesarios para llegar a él". Ph. DelHaYE, "Dignidad de la persona humana", en G. BARAUNA (dir.), o.c., 318.

62. J. MourouX, "Sobre la dignidad de la persona humana", Y. M.-J. CongaR -M. Peuchmaurd (dirs.), o.c..,II, 302. 


\section{1. La realidad del pecado}

El número 10 del texto conciliar señala como "... los desequilibrios que fatigan al mundo moderno están conectados con ese otro desequilibrio que hunde sus raíces en el corazón humano. Son muchos los elementos que se combaten en el propio interior del hombre." (GS 10a). Más adelante se cita a San Pablo en su carta a los Romanos donde con toda sinceridad describe su propia experiencia de encontrarse esclavizado por el pecado, motivo por el cuál ve que hace el mal que no quiere, y no hace el bien que quiere (Rom 1, 14-15). Esta "alienación"63 experimentada por todo hombre, es la fuente del resto de desequilibrios que padece el mundo.

Según J. L. Ruiz de la Peña:

"El sentimiento de fractura o desgarramiento en el hombre y en la realidad social, del que da fe la reflexión extrateológica, delata la existencia de un desorden radical, que se resiste a ser absorbido por una terapéutica meramente humana y que, por ello, desvela una patética indigencia de salvación"64.

El número 13 al desarrollar específicamente el tema del pecado mostrando la paradoja humana, y su excelsa dignidad junto con su miseria, da continuidad a lo expuesto en el párrafo segundo del número 1265 . El número 13, en sintonía también con el número 10, plantea una explicación "agustiniana" del pecado ${ }^{66}$, dado que afirma que "el hombre, en efecto, cuando examina su corazón, comprueba su inclinación al mal y. se siente anegado por muchos males" (GS 13a). La «inclinación al mal» es una experiencia de todo hombre. Sin embargo, el texto conciliar no se queda en suscribir y señalar esa experiencia humana de división interna sino que también busca demostrar la convergencia entre la revelación y la experiencia humana, que han "de escla-

63. El término lo recogemos seg"un el sentido que le dan M. FLICK- Z. Alszeghi, Antropología teológica, ed.c., 220. $1991,158$.

64. J. L. RuIZ DE LA PEÑa, El don de Dios. Antropología teológica especial, Santander

65. "El párrafo dos ha sido añadido al texto primitivo, para subrayar la «paradoja contradictoria» (de grandeza y miseria) que el hombre constituye para nuestros contemporáneos, paradoja que la Iglesia sufre dolorósamente y que sólo la Palabra de Dios es capaz de esclarecer en profundidad". J. Mouroux, "Sobre la dignidad de la persona humana", en Y. M.-J. CONGAR - M. Peuchmaurd (dirs.),o.c., II, 287.

66. Cf. J. I. GonZÁlez Faus, Proyecto de hermano, ed. c., 360. 
recerse recíproca y complementariamente" 67 , porque "a la luz de esta revelación, la sublime vocación y la miseria profunda que el hombre experimenta hallan simultáneamente su explicación" (GS 13c).

\section{2. Origen del pecado}

Dios ha creado al hombre "en la justicia", o sea, "en un estado de libertad intacta y de amistad con él"68. Dios no es el origen de pecado humano: "[El hombre]...cuando examina su corazón, comprueba su inclinación al mal y se siente anegado por muchos males, que no pueden tener su origen en su santo Creador" (GS 13a), porque Dios es infinitamente bueno. Por su parte, el "hombre tampoco se halla por sí mismo en el comienzo del mal". Pero qué ocurrió para encontrarnos en esta situación, el texto conciliar sin entrar en la discusión de temas $\operatorname{concretos}^{69}$ se refiere para solucionar el problema a la Escritura:

"El hombre, sin embargo, por instigación del demonio, en el propio exordio de la historia, abusó de su libertad, levantándose contra Dios y pretendiendo alcanzar su propio fin al margen de Dios" (GS 13a).

El texto de "la tentación y la caída" narrado por Gen 3, 1-5, es citado indirectamente como respuesta a la pregunta por el origen del pecado. El hombre seducido por el Maligno, rompe la relación con Dios, por lo que Dios se convierte en un ser extraño, pierde la confianza en Él, y procura por sus propias fuerzas conseguir lo que está reservado a $\operatorname{Dios}^{70}$, la vocación divina del hombre se trastoca, y se aleja de Dios.

Ante esta situación de la humanidad el número 13, siguiendo a San Pablo en Rom 1,21-25, llega a afirmar como los hombres "conocieron a Dios pero no le glorificaron como a Dios. Oscurecieron su estúpido corazón y prefirieron servir a la criatura, no al Creador". (GS 13a).

67. J. L. Ruiz de la PeÑa, El don de Dios, ed.c., 158.

68. J. Mouroux, "Sobre la dignidad de la persona humana", en Y. M.-J. ConGAR - M. Peuchmaurd (dirs.),o.c., II, 292.

69. Cf. L. F. LADARIA, Teología del pecado original y de la gracia, Madrid 1993, 106, y J. Mouroux, "Sobre la dignidad de la persona humana", Y. M.-J. Congar y M. PEuChmaurd (dirs.),o.c., II, 291.

70. Cf. P. SCHOONENBERG, "El hombre en pecado", en Mys. Sal., II/2, 999. 


\section{3. Consecuencias del pecado}

Dios es el que da el sentido pleno al hombre, y si se le rechaza, ello implica una serie de inevitables consecuencias a todos los niveles. De esta modo, con un lenguaje personalista ${ }^{71}$, el concilio llega a afirmar: "Al negarse con frecuencia a reconocer a Dios como su principio, rompe el hombre la debida subordinación a su fin último, y también toda su ordenación tanto lo que toca a su propia persona como a las relaciones con los demás y con el resto de la creación." (GS 13a).

Lo que sigue son los efectos del pecado en la persona al romper su relación con Dios, dejaremos para más adelante los efectos del pecado sobre las relaciones con los otros hombres y con la creación. Por lo que respecta a Dios, señalamos estas consecuencias: División interna del corazón humano, muerte del alma y el ateísmo o increencia.

\section{3. 1. La división interna del corazón humano}

La primera consecuencia es una lucha tremenda dentro del corazón del hombre, a la que ya aludíamos anteriormente, entre el bien y el mal, y la sensación de impotencia derivada del hecho de que el hombre se siente incapaz de "domeñar con eficacia por sí solo los ataques del mal, hasta el punto de sentirse aherrojado entre cadenas" (GS 13b). Esta inevitable atadura al pecado se debe al pecado de Adán, al "primer pecado"72; un lastre para la historia de la humanidad, y una realidad esencial al hombre por el hecho de nacer hombre.

Según K. Rahner el hombre nace en "una situación universal de perdición que implica a todo hombre antes de la decisión de su propia libertad personal; situación que, sin embargo, es fruto de una determinación histórica y no constitutivo esencial; es provocada por el hombre y no simplemente dada por

71. Cf. J. L. LORDA, Antropología, ed.c.,84.

72. El concilio no usa el término "pecado original", por lo que no se usará esta terminología, sin embargo usa el término "primer pecado" que se describe como hemos visto en GS 13; en el 18 encontramos que al hablar de la muerte se puede leer: "la fe cristiana enseña que la muerte corporal, que entró en la historia a consecuencia del pecado" (GS 18b); y será en el número 22 , en el segundo párrafo, en el que se menciona explícitamente otra vez el término "primer pecado" refiriéndose al cometido por Adán y narrado en el Génesis. 
el hecho de la creación"73. En otra obra suya podemos leer: "...cada hombre tiene la impresión de decidirse, de tener que encontrarse a sí mismo y a Dios en un mundo que está codeterminado por la culpa y la claudicación culpable de todos" $" 74$.

Ante esta situación de pecado la constitución del hombre se halla dañada a consecuencia del pecado. La inteligencia se encuentra "parcialmente oscurecida y debilitada" (GS 15 a), la conciencia "se va progresivamente entenebreciendo por el hábito del pecado" (GS 16), y la libertad se encuentra "herida por el pecado" (GS 17).

La tradición de la Iglesia afirma que el hombre en el bautismo se renueva, vuelve a nacer, y al usar de su libertad, ayudado por la gracia de Dios, puede aceptar a Dios como su Creador, porque "...el Señor vino en persona para liberar y vigorizar al hombre, renovándole interiormente y expulsando al príncipe de este mundo (cf. Jn 12,31), que le retenía en la esclavitud del pecado." (GS 13b).

El hombre también puede decir no a Dios, de modo que "cada cual tendrá que dar cuenta de su vidạ ante el tribunal de Dios según la conducta buena o mala que haya observado" (GS 17).

\section{3. 2. La muerte}

Otra consecuencia del pecado, que se trata en el número 18 de la constitución pastoral, es que genera la muerte. Según la Escritura la muerte corporal entró en el mundo por el pecado. Tal y como dice Ph. Delhaye: "El carácter trágico de la muerte está unido al del pecado y revela toda su profundidad, porque, sin él, el hombre hubiera estado exento de aquella"75.

La muerte hoy en día es un hecho que se quiere esconder, y a la vez ostenta un gran protagonismo en la actualidad ${ }^{76}$. Es una experiencia común a todo hombre, el cuèrpo material tiende a su desaparición y disolución progresiva, deterioro que a pesar de los adelantos técnicos no se consigue detener, llegando al trágico fin de la muerte.

73. K. RAHNER, Consideraciones teológicas sobre el monogenismo, en Escritos de Teología, I, Madrid 1961, 307.

74. ID., Curso fundamental sobre la fe, ed.c., 137.

75. Ph. Delhaye, "La dignidad de la persona humana", en G. Barauna (dir.), o.c., 311.

76. Cf. J. L. RuIZ DE LA PEÑA, "Muerte", en J. L. RuIZ DE LA PEÑA, Una fe que crea cultura, Madrid 1997, 323. 
La muerte es el "máximo enigma de la vida humana" (GS 18a), es "...el tema de la muerte, inevitable pero siempre aborrecida", para todos los hombres en todos los tiempos. La muerte es la enemiga más radical del hombre, que constantemente se hace presente en nuestra vida y se anticipa para recordar que se encuentra al final del camino, es también el signo de otra muerte - la muerte eterna -, más terrible todavía, porque nos separa de quien es la fuente, el fin, la dicha del ser humano ${ }^{77}$.

El hombre en su interior no acepta la muerte como fin último porque "la semilla de eternidad que en sí lleva, por ser irreductible a la sola materia, se levanta contra la muerte(...). Dios ha llamado y llama al hombre a adherirse a El con la total plenitud de su ser en la perpetua comunión de la incorruptible vida divina" (GS 18a-b). La esperanza cristiana radica en el hecho de que Cristo ha vencido la muerte, y nos ha liberado de la muerte con la suya, "...ha sido Cristo resucitado el que ha ganado esta victoria para el hombre, liberándolo de la muerte con su propia muerte." (GS 18b).

Ante esto algún autor ha llegado a decir: "A este abismo de miseria sólo otro abismo puede responder: el del misterio cristiano. Dios no ha hecho la muerte, ha creado al hombre para la inmortalidad, le llama a la comunión bienaventurada, y eterna con El. Ha realizado ya esto en Jesucristo - el Dios Hombre en quien todos nosotros somos elevados, que ha «gustado» y atravesado la muerte, para librarnos de ella, desde dentro mismo de nuestra miseria; y que ha resucitado como garantía (...). Esta [la muerte] se convierte, por tanto, en Jesucristo, no en un término, sino en un tránsito..."78.

\section{3. 3. Del ateísmo o increencia 79}

En la constitución pastoral podemos leer: "...muchedumbres cada vez más numerosas se alejan prácticamente de la religión. La negación de Dios o de la religión no constituyen, como en épocas pasadas, un hecho insólito e

77. Cf. J. Mouroux, "Sobre la dignidad de la persona humana", en Y. M.-J. ConGAR - M. Peuchmaurd (dirs.),o.c., II, 304.

78. Ib., 305.

79. Este apartado merecería un mayor detenimiento pero exclusivamente nos limitaremos a hacer una breve exposición de lo que dice el concilio en los números 19 y 20 de la Gaudium et spes, para iluminar mejor nuestro tema. De hecho "el concilio ni podía ni intentaba hacer un análisis completo del ateísmo contemporáneo y de sus formas y causas reconociendo su complejidad". V. MiAno, "El ateísmo y el Magisterio de la Iglesia", en G. GIRARDI (dir.), El ateísmo contemporáneo, IV, Madrid 1971, 78. 
individual; hoy día, en efecto, se presentan no rara vez como exigencia del progreso científico y de un cierto humanismo nuevo" (GS 7c). Este texto nos sitúa ante un hecho novedoso ${ }^{80}$, hoy día más importante aún si cabe que cuando se celebró el concilio, pero significativo ya entonces. El ateísmo, y la indiferencia religiosa son un alejarse de Dios, un rechazo de su amor. Esta situación, en la que se ve envuelto el hombre, es tratada, no con un tono condenatorio, sino intentando comprender sus causas y motivos y, consecuentemente intentando un diálogo. Específicamente al estudio del tema de este apartado están dedicados los números 19 y 20, dado que el número 21 tratará de la actitud de la Iglesia ante el ateísmo.

El número 19 comienza afirmando que "la dignidad humana consiste en la vocación del hombre a la unión con Dios" (GS 19a), sin embargo hoy día ocurre que es un hecho generalizado el que muchos "...se desentienden del todo de esta íntima y vital unión con Dios o la niegan de forma explícita" (GS 19a). Lo que nos interesa para este apartado es el punto desde el que parte para desarrollar la posterior reflexión, o sea, la certeza de que hay muchas personas que ante el fenómeno religioso se tornan indiferentes, o explícitamente lo niegan, es lo mismo que decía anteriormente el número 7 . Posteriormente el número 19 expondrá las diversas causas que provocan el ateísmo. Una agrupación de las causas del ateísmo expuestas en este número 19 podría ser la siguiente: "De forma más general el motivo del ateísmo es la exasperación de la autonomía humana. Otras veces es la supuesta imposibilidad de conocer de alguna forma a Dios o el no ver por qué haya que ocuparse de él. No faltan tampoco los que conscientemente evitan plantearse el problema. Finalmente, los hay también que rechazan una imagen falsa de Dios, muy distinta de la del Evangelio, o que adjudican un valor absoluto a algunos bienes humanos." 81

El número 20, por su parte, comienza con la convicción de que el ateísmo moderno no es sólo algo personal, sino que "reviste también la forma sistemática, la cual, dejando ahora otras causas lleva el afán de autonomía humana hasta negar toda dependencia del hombre respecto de Dios" $(\text { GS20a })^{82}$. Desde esta perspectiva Dios molesta al hombre, o al menos deja

80. "La difusión masiva de la irreligión militante o de la indiferencia religiosa es una de las grandes novedades de nuestra época, de la que el concilio levanta acta." J. Folliet, "La condición del hombre en el mundo de hoy", en G. BARAuna (dir.), o.c., 296.

81. R. Sigmound, o.c., 199.

82. V. Miano ve dos tipos de ateísmo emplícitos en las palabras del concilio el que radica en el pensamiento de Nietzsche y el existencialismo, y el marxista. Cf. V. Mrano, o.c., 79. 
de tener relevancia para la vida humana, porque "... el hombre es el fin de sí mismo..." (GS 20a).

\section{LA FILIACIÓN DIVINA EN CRISTO}

\section{EL "CRISTOCENTRISMO"83 DE LA CONSTITUCIÓN PASTORAL "GAUDIUM ET SPES"}

En el discurso de apertura de la segunda sesión conciliar Pablo VI, ante la reanudación del trabajo iniciado, se planteó tres interrogantes: por dónde empezar a caminar, qué rumbo tomar, y cuál sería el objetivo del concilio ${ }^{84}$. La respuesta que dio fue situar a Cristo en el centro de la reflexión conciliar, porque la Iglesia no puede más que proclamar constantemente que Cristo es "...de quien venimos, por quien vivimos y a quien vamos" 85 .

Juan Pablo II subraya explícitamente que el magisterio conciliar "...es cristocéntrico en todos sus aspectos y, por eso, está profundamente enraizado en el Misterio trinitario"86. Para la Iglesia quien se encuentra siempre en el centro de su vida y misión no es otro que Cristo, y, por supuesto, esta perspectiva cristocéntrica tiene que estar presente en el diálogo de la Iglesia con el mundo. El gran mensaje de la constitución pastoral Gaudium et spes es que Cristo en su muerte nos ha revelado definitivamente la naturaleza y el destino de la humanidad y del mundo ${ }^{87}$.

Este mensaje aparece desde el comienzo de la constitución pastoral, donde se puede leer que Cristo es "...quien vino al mundo para dar testimo-

83. Por cristocentrismo queremos indicar lo definido por la Comisión Teológica Internacional en 1981. "El cristocentrismo, dejando aparte nociones menos propias, connota propiamente la cristología de Jesús de Nazaret, la cual, tomada en su intención más profunda, expresa la «singularidad» de Jesús; pero la singularidad de Jesús concuerda propiamente con la revelación de la Trinidad, ya que, por una parte, se define por la singular relación del mismo Jesús con el Padre y el Espíritu Santo; y consecuentemente, por otra parte, por su singular manera de ser para con los hombres." COMISIÓN TEOLÓGICA INTERNACIONAL, TeologíaCristología-Antropología, en COMISIÓN TEOLÓGICA INTERNACIONAL, Documentos 19691996, Madrid 1998, 248.

84. Cf. PABLo VI, Salvete, Fratres Alocución en la apertura de la segunda sesión del concilio Vaticano II, 29-IX-1963, en AAS. 55/2 (1963) 845-846; AS. II/2, 187.

85. Ib.

86. Juan Pablo II, Cruzando el umbral de la esperanza, Barcelona ${ }^{4}$ 1994, 145.

87. Cf. JUAN PABLo II, "La «Gaudium et spes» un abrazo al mundo moderno", en Ecclesia 55 (1995) 1828. 
nio de la verdad..."(GS 3b). La verdad a la que se refiere el concilio no es otra que la revelada en Él. La búsqueda de la verdad pertenece a "la naturaleza misma del hombre" 88 , o sea en el interior del hombre, por el hecho de ser hombre existe una tendencia a dar sentido a la vida, tal y como veíamos anteriormente.

Dios que llama al hombre a vivir con Él, y que ha insertado en el corazón humano la vocación divina, revela al hombre al propio hombre en Cristo, quiere reunir junto a sí a la fraternidad universal de los hombres, y la recapitulación de todo en Cristo ${ }^{89}$.

En la Gaudium et spes, se puede apreciar una estructura cristocéntrica. Todo lo que se dice culmina en un pasaje cristológico, que ilumina, o da sentido, a lo expuesto anteriormente. Ya hemos indicado antes cómo aparece Cristo en la Introducción, cómo es el que revela al hombre cuál es su destino y el del mundo. En la Exposición preliminar se acaba presentando a Cristo como la clave desde la que esclarecer el misterio del hombre y cooperar en el hallazgo de soluciones que respondan a los principales problemas..." (GS 10b).

La Primera parte al finalizar cada uno de sus cuatro capítulos presentará un número dedicado a Cristo ${ }^{90}$. Por su lado, la Segunda parte hablará en casi todos los capítulos sobre Cristo ${ }^{91}$. En la Conclusión recuerda como Cristo se ha hecho nuestro hermano, y nos ha abierto la puerta a la esperanza de vivir en Dios ${ }^{92}$.

88. Fides et Ratio, 3 .

89. Cf. GS $22 \mathrm{a} ; 3 \mathrm{~b} ; 45 \mathrm{~b}$

90. GS 22, 32, 38, 45. El capítulo tercero no concluye con el $\mathrm{n}^{\circ} 38$ Perfección de la actividad humana en el misterio pascual, sino con el 39 Tierra nueva y cielo nuevo cuya esperanza nos la da Cristo.

91. GS 52 g, 58d, 61a, 72, 78c. El único capítulo que no habla de Cristo es el Capt. IV sobre La vida en la comunidad política, su explicación podría radicar en que ya habría sido suficientemente tratado el tema de como en Cristo se perfecciona y se consuma la índole comunitaria del hombre en GS 32 .

92. Cf GS 93a. 


\section{1. Cristo da sentido a la historia humana ${ }^{93}$}

El hombre que camina en la historia, que vive en el espacio y en el tiempo, descubre el sentido de esa historia en Cristo. Cristo es "la clave, el centro y el fin de toda la historia humana" (GS 10b). Se descubre en esta concepción de la historia un carácter dinámico. Este dinamismo de la historia no es un suceder anárquico de acontecimientos, sino la convicción de que la historia está compuesta de elementos "cambiantes" en la superficie cada vez más acelerados, pero bajo esos hay otros más profundos y "permanentes, que tienen su último fundamento en Cristo, quien existe ayer, hoy y para siempre" (GS $10 \mathrm{~b})$. Esto exige al creyente juzgar los hechos de otra forma, para descubrir al Señor que llama al hombre en la historia.

La encarnación del Verbo acontece en la historia concreta de un pueblo, vive como uno más, e incluso se somete a la ley humana. Jesús participó de la vida social humana, o sea de la historia del hombre a la que da sentido.

\section{2. La vocación divina del hombre revelada en Cristo}

A las grandes preguntas suscitadas por el hombre sobre el sentido de su vida, Cristo es la respuesta, esclarece el misterio del hombre. Cristo nos revela que Dios es amor ${ }^{94}$, y que en su infinita misericordia nos ha amado tanto que ha enviado a su Hijo, para sacarnos de nuestra dispersión, para recomponer la división interna del corazón humano, y el fracaso de las propias fuerzas para vencer el dolor y la muerte.

Cristo es el "punto de convergencia hacia el cual tienden los deseos de la historia y de la civilización, centro de la humanidad, gozo del corazón humano y plenitud total de sus aspiraciones" (GS 45b). M.D. Chenu, al interpretar este número 45 de la constitución pastoral, dice que: "...la perspectiva formal cristológica del texto (...) se inscribe en una visión «teológica» última,

93. "El Verbo de Dios, por quien fueron hechas todas las cosas, hecho El mismo carne y habitando en la tierra, entró como hombre perfecto en la historia del mundo, asumiéndola y recapitulándola en sí mismo" (GS 38a). Véase también J. L. ILLANES, "Cristo, centro de la historia", en Burgense 26/1 (1985) 75-103.

94. Cf. GS $32 b$ y GS 38 a. 
según la cual la encarnación histórica del Verbo es la vía escogida por Dios, para que, en su amor, la creatura emanada de El retorne a su Creador"95.

Cristo, por tanto, aparece como el "principio de vida"(GS 52g), pero no de una vida abocada a la muerte, sino de una vida que tras haber vencido a la muerte plenifica al hombre, le hace un hombre nuevo que comparte la vida divina como hijo en el Hijo.

\section{CRISTO, EL HOMBRE NUEVO (GS 22)}

Gaudium et spes 22 es el número con mayor altura teológica de todo el texto conciliar ${ }^{96}$. La «teología cristocéntrica» 97 que se expresaba aquí es el deseo de muchos Padres conciliares de que Cristo apareciera como fundamentación de la antropología expresada en este primer capítulo. Este deseo no sólo se recogió en la constitución pastoral, sino que ha sido acogido después por Juan Pablo II como elemento central de su pensamiento antropológico $^{98}$.

Para los Padres conciliares era necesario explicar cómo el hombre ha sido creado a imagen de Dios y esta dignidad ha sido restaurada en Cristo ${ }^{99}$. A este respecto, hay que constatar como en el número 12 la creación del hombre a imagen de Dios se basa solamente en citas del A.T. y ninguna del N.T., las razones de esta opción parecen ser de tipo pastoral ${ }^{100}$. En el número

95. M.-D. CHENU, "Misión de la Iglesia en el mundo contemporáneo", en G. BARAUNA (dir.), o.c., 384-385.

96. Cf. J. Ratzinger, "Ertes Kapitel des Ersten Teils", en AA.VV. Lexicon fur Theologie und Kirche. Das zweite Vatikanische Konzil, III, Freiburg-Basel-Wien 1968,350. De esta misma opinión es L.F. LADARIA, "El hombre a la luz de Cristo en el concilio Vaticano II", en R. LATOURELlE (dir.), o.c., 707.

97. «Christozentrischen Theologie», término tomado de J. RATZINGER, o.c.,350.

98. Nos vale recordar como comienza su primera encíclica: "El Redentor del hombre, Jesucristo, es el centro del cosmos y de la historia" (RH 1), y más adelante afirmará "...la única orientación del espíritu, la única dirección del entendimiento, de la voluntad y del corazón es para nosotros ésta: hacia Cristo "(RH 7).De hecho tal y como afirma E. J. Fernández: "Toda la encíclica Redemptor Hominis es un gran comentario a este pasaje del Concilio,...". E.J. FERNÁNDEZ, "El pensamiento trinitario de Juan Pablo II", en Estudios trinitarios 22 (1988) 284.

99. Cf. L.F. LADARIA, El hombre como tema teológico. Cuestiones actuales de antropología teológica, Roma 1994, 21.

100. Cf. Ib.; Según W. Kasper, "se aspiraba, en el fondo, con todos esos procesos y reflexiones, a una argumentación teológica, basada en la historia de la salvación, que no dejara de explicar la situación actual; a un lenguaje que formulara lo específicamente católico y que pudiera ser adoptado también por los no católicos y no cristianos." W. KASPER, "La antropo- 
13b aparece esta relación, después de hablar del pecado, en este texto: "...el Señor vino en persona para liberar y vigorizar al hombre, renovándole interiormente y expulsando al príncipe de este mundo (Cf. Jn 12,31) que le retenía en la esclavitud del pecado." (GS 13b).

El mismo título del número Cristo, hombre nuevo parece señalar la necesidad de una renovación en Cristo, o sea, renovar la historia de la humanidad donde la relación entre Dios y los hombres no ha sido pacífica sino conflictiva a causa del pecado ${ }^{101}$. La sintonía entre la creación del hombre a imagen de Dios, y la restauración de esa imagen en Cristo es, a mi modo de ver, la clave de lectura de este número. Pero no es sólo una restauración a un estado primero sin más, sino que la revelación de Cristo aporta algo nuevo, una relación nueva entre Dios y el hombre por la que éste último se convierte en hijo por adopción.

Nos detendremos en un análisis pormenorizado de los seis párrafos de los que consta este número 22 , debido a su influencia en la teología posterior ${ }^{102}$, y para profundizar en esa nueva relación de filiación del hombre con Dios revelada en Cristo.

\title{
2. 1. PÁRRAFO PRIMERO: "El misterio del hombre sólo se esclare- ce en el misterio del Verbo encarnado"
}

\begin{abstract}
"En realidad, el misterio del hombre sólo se esclarece en el misterio del Verbo encarnado. Porque Adán, el primer hombre era figura del que había de venir es decir Cristo nuestro Señor, Cristo, el nuevo Adán, en la misma revelación del misterio del Padre y de su Amor, manifiesta plenamente el hombre al propio hombre y le descubre la sublimidad de su vocación. Nada extraño, pues, que todas las verdades hasta aquí expuestas encuentren en Cristo su fuente y su corona"
\end{abstract}

En la última frase del párrafo se nos presenta la clave de interpretación de todo el primer capítulo, "...cuanto se ha dicho del hombre se ha dicho eminentemente de Cristo. Está clara por tanto la intención del concilio"103. Desde

pología teológica de la Gaudium et Spes", en Laicos hoy 39 (1996) 49.

101. Cf. L. F. LADARIA, El hombre como tema teológico, ed.c., 21-22. $32-42$.

102. Vease en este sentido L. F. LADARIA, Introducción a la antropología teológica, ed.c.,

103. L.F. LADARIA, "El hombre a la luz de Cristo en el concilio Vaticano II", en R. LATOURELle (dir.), o.c., 708. 
esta clave de interpretación cristocéntrica lo primero que nos encontramos es con una primera frase muy conocida actualmente ${ }^{104}$. Se habla del hombre a la luz de Cristo, el cual no es una luz externa al hombre, sino que con su Encarnación ha iluminado al hombre el misterio del hombre. La Encarnación del Verbo es un acontecimiento clave en la historia de la humanidad, gracias a ella "...el misterio de Cristo y el del hombre forman, en definitiva, un sólo misterio. Y por eso el concilio, de acuerdo con S. Pablo, pone directamente en relación el misterio del primer hombre y el del Verbo encarnado" 105.

"Porque Adán, el primer hombre, era figura del que había de venir, es decir, Cristo", para fundamentar esta afirmación el concilio cita dos textos, uno de Pablo, Rom 5, 14, y otro de Tertuliano De carnis resurrectionis $66^{106}$. Ambos textos son muy importantes para la comprensión de este párrafo por lo que nos detendremos en su interpretación.

El contexto de Rom 5, 14 es 5,12-21107, todo él es de gran importancia para la comprensión de la doctrina eclesial sobre el pecado original.

La tipología Adán-Cristo se usa como elemento que estructura el texto en su integridad. En Rom 5,12-21, lo que persigue Pablo frente a las tendencias judaizantes es atribuir a Cristo la función mediadora y salvadora que los judíos atribuían a la ley108.

Pablo usa, para conseguir su objetivo, un argumento propio de la teología judía: por Adán entró el pecado en el mundo. De este modo, frente a las tendencias judaizantes, Pablo señala que si Dios ha permitido que por uno entrase el pecado en el mundo, con mayor razón lo permitirá para que se salve.

Los versículos 13-14 subrayan la universalidad del pecado. El pecado afecta a todos, hayan conocido la ley o no, tal como se afirma al final del ver-

104. En el pensamiento de JUAN PABLo II esta frase del concilio tiene una gran importancia. Desde su primera encíclica Redemptor hominis ( números $8,13,18$ ) hasta la última Fides et ratio (59), es un punto de referencia constante de su enseñanza pontificia.

105. J. MourouX, "Sobre la dignidad de la persona humana", en Y. M.-J. CongAR - M. Peuchmaurd (dirs.), o.c., II, 306.

106. "Quodcumque enim limus exprimebatur, Christus cogitabatur homo futurus". Tertuliano, De carnis resurrectionis 6, en PL 2, 282.

107. Para un análisis más detallado de estos versículos me remito al elaborado por $\mathrm{M}$. Flick-Z. Alszeghy, El hombre bajo el signo del pecado.Teología del pecado original, Salamanca 1972, 56-71; J. L. RuIZ DE LA PEÑA, El don de Dios, ed.c., 86-108.

108. Cf. J. L. Ruiz DE LA PEÑA, El don de Dios,ed.c., 96. 
sículo 12: "...por cuanto todos pecaron". El versículo 14 subraya que el pecado es anterior a la ley porque la muerte, como expresión del pecado y de su fuerza, estaba también presente desde Adán hasta Moisés ${ }^{109}$.

Al final del versículo usa la tipología Adán-Cristo. Adán como el primer hombre, es figura de Cristo, con este final se reclama la atención protológica del tema pecado-gracia, y su dimensión dinámica ${ }^{110}$. El texto conciliar reclama esta dimensión protológica al citar un texto de Tertuliano: "...en lo que se expresaba en el fango, se pensaba en Cristo que debía hacerse hombre"111.

La Comisión Teológica Internacional y L. F. Ladaria nos hacen caer en la cuenta que lo que escribió Tertuliano es compartido por S. Ireneo ${ }^{112}$, ambos afirmaban que el primer hombre plasmado por las manos de Dios del barro de la tierra, reproducía ya la imagen de Cristo que se iba a encarnar ${ }^{113}$. Este pensamiento común a ambos autores fundamenta la interpretación que hace L. F. Ladaria a este primer párrafo, y que comparto:

"No se explica a Cristo por Adán, sino Adán por Cristo. Por ello sólo por medio de Cristo podemos saber qué es el hombre(...) [Cristo] revela también con su vida la vocación del hombre: estamos desde siempre llamados a la comunión con Dios, a ser hijos suyos en el Hijo" 114 .

M. Flick y Z. Alszeghy en este sentido afirmarán que "...el pecado del primer Adán fue permitido para que, por medio del segundo Adán, la vida divina se comunicase de una manera más perfecta de como habría sucedido por medio del primer Adán"115. Cristo se vuelve un elemento esencial, es más,

109. Cf. L.F. LADARIA, Teología del pecado original y de la gracia, ed. c., 74.

110. "La concepción cristiana del hombre como historia desde el primer Adán al segundo elimina el concepto filosófico de una naturaleza esencial invariante del hombre, transformándolo en historicidad o, más bien, en la dinámica de esa historia concreta". W. PANNENBERG, "Fundamento cristológico de una antropología cristiana", en Concilium 9/2 (1973) 401-402.

111. Sobre la poca fortuna que tuvo esta línea de pensamiento en siglos posteriores podemos ver: L. F. LADARIA, Introducción a la antropología teológica, ed.c., 66-67.

112. Cf. COMISIÓN TEOLÓGICA INTERNACIONAL, El cristianismo y las religiones (1996), en COMISIÓN TEOLÓGICA INTERNACIONAL, o.c., 575; L.F. LADARIA, "El hombre a la luz de Cristo en el concilio Vaticano II", en R. LATOURELle (ed.), o.c., 708.

113. Para un mayor estudio del tema nos remitimos a A. ORBE, Antropología de san Ireneo, Madrid 1969,99-105.

114. L.F. LADARIA, "El hombre a la luz de Cristo en el concilio Vaticano II", R. LATOURELle (dir.), o.c., 708.

115. M. FliCK-Z. AlsZEGHY, Antropología teológica, ed.c., 320. 
es el elemento decisivo para comprender aquello que somos, la dignidad de nuestra vocación, la vocación a vivir en el seno del Padre como hijos.

\section{2. PÁRRAFO SEGUNDO: Cristo Imagen de Dios invisible y hom- bre perfecto}

"El que es imagen de Dios invisible (Col 1,15) es también el hombre perfecto, que ha devuelto a la descendencia de Adán la semejanza divina, deformada por el primer pecado. En él, la naturaleza humana asumida, no absorbida, ha sido elevada también en nosotros a dignidad sin igual. El Hijo de Dios con su encarnación se ha unido, en cierto modo, con todo hombre. Trabajó con manos de hombre, obró con voluntad de hombre, amó con corazón de hómbre. Nacido de la Virgen María, se hizo verdaderamente uno de los nuestros, semejante en todo a nosotros, excepto en el pecado".

El párrafo comienza con dos afirmaciones sobre Cristo: "imagen de Dios invisible" y "hombre perfecto".

La afirmación de Cristo como imagen de Dios invisible recuerda al inicio del capítulo primero, en el número 12 el hombre era definido como imagen de Dios. La cita de Col 1,15 que aparece en el texto nos hace volver la vista también sobre GS 10b, que cita a pie de página ese mismo texto. En Col 1, 15 ese Dios que no puede ser visto por el hombre, según la tradición veterotestamentaria, se puede ver en su Hijo ${ }^{116}$, porque "...en el rostro de Jesucristo resplandece el esplendor de Dios Padre invisible"117. Para J. L. Ruiz de la Peña en este texto, "...se nos revela en una exacta reproducción que participa de todo el poder de deslumbramiento propio del original "118. El texto de 2 Cor 4 , 4, que se cita a pie de página, va en el mismo sentido. Se subraya que Cristo como "imagen de Dios" no se limita a ser una simple copia, es "una especie

116. "En los textos de Cristo como imagen de Dios interpretamos la expresión como el momento de comunicación/revelación del Padre hacia el hombre. Cristo es imagen del Padre porque lo hace accesible a quien no es Dios mismo" F. PASTOR RAMOS, "Cristo imagen del Padre", en Estudios trinitarios 22 (1988) 397.

117. COMISIÓN TEOLÓgICA INTERNACIONAL, Documentos papales sobre la Comisión Teológica Internacional.Apéndice I, en COMISIÓN TEOLÓGICA INTERNACIONAL, o.c., 631 .

118. J. L. RuIZ DE LA PENAa, Imagen de Dios, ed.c., 79. 
de reproducción que irradia esplendor (...) es la manifestación fidedigna e inequívoca de la divinidad"119.

Para Pablo, la imagen de Dios es sobre todo Cristo, y la imagen de Dios en el hombre es aquella semejanza con Dios que Cristo restaura en el hombre. Llegados a este punto, conviene recordar este texto del evangelio de Juan: "El que me ha visto ha visto al Padre" (Jn 14, 9), en el que Jesús tal y como dice W. Kasper "es la autodefinición escatológica de Dios en persona"120; o como afirma J. Mouroux: "...cuando el Verbo se encarna, entra en el mundo a la vez como imagen particular en medio de la inmensidad de las otras, y como el tipo, eterno e increado, de todas las imágenes creadas"121.

Cristo como "el hombre perfecto". El Concilio usa cuatro veces este concepto en GS $22,38,41,45$, con una diferencia, en GS 22 y 41 en latín aparece la expresión "homo perfectus", y otras dos veces como "perfectus homo" en GS 38 y 45. Situar el adjetivo delante del nombre puede decir que Jesús es "perfectamente hombre"122; decir sin embargo "hombre perfecto", añade algo: "es el hombre perfecto123". Jesús es Aquel en el que la humanidad alcanza el grado más alto, Aquel que realiza la esencia humana en su plenitud, y por eso el misterio del hombre se ilumina por medio de Cristo. Cristo "ha devuelto a la descendencia de Adán la semejanza divina que había sido deformada por el primer pecado", esta afirmación, según J. Mouroux, indica que Cristo es "...capaz de restaurar en el hombre, no la imagen, que es indestructible (...), sino la semejanza, que es la transfiguración sobrenatural de la imagen, originalmente concedida al hombre, alterada a partir del primer pecado, restaurada en Jesucristo, mediante el cual puede volver a hacerse conforme con la imagen que es Cristo"124.

119. Ib., 78-79.

120. W. KASPER, El Dios de Jesucristo, Salamanca 1985, 148.

121. J. MourouX, "Sobre la dignidad de la persona humana", en Y. M.-J. ConGAR y M. Peuchmaurd (dirs.),o.c., II, 307.

122. Esto aparece en la enseñanza tradicional de la Iglesia de los primeros concilios de la Iglesia, como por ejemplo el Concilio de Calcedonia que afirma que Jesucristo es "...el mismo perfecto en la divinidad y el mismo perfecto en la humanidad", en Denzinger, 148.

123. "El concilio Vaticano II ha añadido, creo, un nuevo matiz: esta humanidad completa es perfecta, es decir, es ejemplar, paradigmática. " L.F. LADARIA, Introducción a la antropología teológica, ed.c., 31 .

124. J. Mouroux, "Sobre la dignidad de la persona humana", en Y. M.-J. CONGAR - M. Peuchmaurd (dirs.),o.c., II, 307. 
La naturaleza humana que Cristo asumió no fue absorbida por la divinidad ${ }^{125}$; de modo parecido "...nuestra naturaleza humana no desaparece ni se diluye en el contacto con él"126, sino que queda elevada, enaltecida a "dignidad sin igual". Cristo sin embargo no sólo se ha unido a una naturaleza humana "en la línea esencialista de los Padres y los antiguos teólogos." 127 , sino que el Concilio afirma que se ha unido, "en cierto modo, con todo hombre". Así, el texto conciliar no sólo se plantea el plano ontológico, "... sino que ha pasado al existencial de la vida humana, de la concreta vida humana"128. Cristo fue en todo semejante, por la Encarnación, a nosotros "excepto en el pecado", citando, en este caso, a pie de página $\mathrm{Hb} 4,15$.

El cómo de esa unión de Cristo con el hombre aparece con imprecisión en el texto conciliar debido a la expresión "en cierto modo". La unión hipostática de Jesús con su humanidad concreta es diferente a la de su unión con los hombres. Tal y como dice L. F. Ladaria: "El hecho de que hoy no tengamos la palabra, no tengamos la fórmula, no debe decir nada contra la cosa. Durante cuatrocientos años, quizá un poco más, hasta el 431, la Iglesia no ha tenido la fórmula, «unión hipostática»: No obstante la fe en la Encarnación existía. (...) El hecho de que nosotros después de dos mil años no tengamos una fórmula, no tengamos una palabra, para definir en un modo claro, lo que quiere decir esta unión de Jesús con la humanidad, no quiere decir que esta unión no sea un hecho"129.

\section{3. PÁRRAFO TERCERO: El Hijo se entregó por nosotros y por nuestra salvación}

"Cordero inocente, con la entrega libérrima de su sangre nos mereció la vida. En El Dios nos reconcilió consigo y con nosotros y nos liberó de la esclavitud

125. En nota a pie el texto conciliar cita los concilios de Constantinopla II, Denzinger, 219; el concilio de Constantinopla III, Denzinger, 291, y el concilio de Calcedonia, Denzinger,148. Con ello se vuelven los ojos a la Tradición más antigua de la Iglesia para afirmar la naturaleza humana asumida por Cristo, y no absorbida, remarcando su ser verdadero hombre.

126. L.F. LADARIA, "El hombre a la luz de Cristo en el concilio Vaticano II", en R. LATOURELLE (ed.), o.c., 708.

127. J. MourouX, "Sobre la dignidad de la persona humana", en Y. M.-J. CONGAR - M. Peuchmaurd (dirs.), o.c., II, 308.

128. L. F. LADARIA, "El hombre a la luz de Cristo en el concilio Vaticano II", en R. LATOURELLE (dir.), o.c., 709.

129. ID., El hombre como tema teológico, ed.c., 30. 
del diablo y del pecado, por lo que cualquiera de nosotros puede decir con el Apóstol: El Hijo de Dios me amó y se entregó a sí mismo por mí (Gal 2, 20). Padeciendo por nosotros, nos dio ejemplo para seguir sus pasos y, además abrió el camino, con cuyo seguimiento la vida y la muerte se santifican y adquieren nuevo sentido".

Todo este párrafo se refiere al misterio de la Redención del hombre por la muerte y resurrección de Jesús, narra, en definitiva, la entrega de Jesús a la muerte por nuestros pecados. El texto se expresa en términos escriturísti$\cos ^{130}$, con la figura del cordero inocente degollado, y los textos que se citan de 2 Cor 5, 18-19 y Col 1, 20-22, se nos presenta un Cristo que nos reconcilia con Dios. El problema del dolor humano, que no tiene sentido para el hombre, encuentra respuesta en el Cristo sufriente, que comparte con nosotros la insensatez del sufrimiento.

En armonía con lo expuesto antes se explícita la relación personal de Cristo con cada uno de los hombres, sin dejar de lado la totalidad de la humanidad. El texto que se cita es el de Gal 2,20 que indica la vida nueva que viven los que han conseguido la misericordia divina en Cristo.

En la última frase de este párrafo se resalta que la venida de Cristo no es sólo para darnos un ejemplo a seguir ${ }^{131}$, o sea una normativa ética. Cristo también abre, por medio de la Pasión, un camino nuevo para la humanidad, que debe ser escogido libremente por cada uno, y que da el sentido pleno a la existencia. No sólo la vida de Jesús, o sea el hecho de encarnarse y vivir como hombre en la historia, da un sentido nuevo a la vida del hombre, sino que también la muerte y el sufrimiento adquieren un nuevo sentido en la Pasión de Cristo.

\section{4. PÁRRAFO CUARTO: El hombre conformado con la Imagen del Hijo}

"El hombre cristiano, conformado con la imagen del Hijo, que es el Primogénito entre muchos hermanos, recibe las primicias del Espíritu (Rom 8,

130. J. Mouroux nos hace caer en la cuenta que el único término no escriturístico es el de "mereció". Cf. J. Mouroux, "Sobre la dignidad de la persona humana", Y. M.-J. CongAR M. Peuchmaurd (dirs.),o.c., II, 308.

131. En este sentido no hay que subestimar de ninguna manera a Cristo como norma de comportamiento, y para confirmarlo debemos tener en cuenta los textos que cita el concilio a pie de página: 1 Pe 2,21; Mt 16,24; Lc 14, 27. 
23), las cuales le capacitan para cumplir la ley nueva del amor. Por medio de este Espíritu, que es prenda de la herencia (Ef 1,14), se restaura internamente todo el hombre hasta que llegue la redención del cuerpo (Rom 8,23). Si el Espíritu de Aquel que resucitó a Jesús de entre los muertos habita en vosotros, el que resucitó a Cristo Jesús de entre los muertos dará también vida a vuestros cuerpos mortales por virtud de su Espíritu que habita en vosotros (Rom 8, 11). Urgen al cristiano la necesidad y el deber de luchar, con muchas tribulaciones, contra el demonio, e incluso de padecer la muerte. Pero, asociado al misterio pascual, configurado con la muerte de Cristo, llegará, corroborado por la esperanza, a la resurrección".

Este párrafo debe analizarse en relación con el segundo, en el que se describía a Jesús como imagen de Dios, y su función de restaurar la semejanza divina del hombre deformada por el pecado. Este cuarto párrafo afirma claramente que el cristiano está "conformado con la imagen del Hijo". El tema de la imagen es interpretado a la luz del Nuevo testamento complemantando la visión del número 12 de la constitución pastoral.

Los textos que se citan a pie de página de Rom 8, 29 y Col 1, 18, nos indica esta complementariedad. Siguiendo la exégesis que hace J. L. Ruiz de la Peña de ambos textos, lo primero que sorprende es que los relaciona por la mención que se hace en Rom 8,29 de Cristo como «imagen» y «primogénito», lo cual acerca el texto de Romanos al himno de Colosenses 132.

Col 1, 18, se puede dividir en dos partes. La primera sería "El es también la cabeza del cuerpo de la Iglesia", e indica que el papel que juega Cristo, como soporte y principio de cohesión de todo lo que existe, hace que Cristo sea calificado por Pablo como «cabeza» del «cuerpo». Con ello se afirma la capitalidad cósmica de Cristo, al añadir «de la Iglesia» indica que tal capitalidad se ejerce eclesiológicamente.

La segunda parte del versículo: "siendo el principio, primogénito entre los mortales para así ocupar el mismo puesto entre todas las cosas", indica como por la resurrección, el Padre ha dado ha su Hijo "una capitalidad ordenada a la colación de los bienes salvíficos, y que tiene como presupuesto el primado cosmológico..." 133.

El resto del número lo que hace es presentar brevemente la escatología cristiana. Cristo da respuesta al enigma de la muerte en general y de cada uno

132. Cf. J. L. RuIz de LA PEÑA, Teología de la creación, Santander 1986, 75.

133. Ib. 
en particular, por la resurrección ${ }^{134}$. El hombre vive en una escatología inaugurada por la resurrección de Cristo, que es la "primicia". Por medio del Espíritu el hombre vive en una tensión escatológica que implica la lucha hasta la muerte contra el mal, la esperanza en la resurrección en la fe de que el Espíritu habita en el corazón humano, y el caminar cotidiano hacia la configuración de Cristo resucitado. Lo que nos interesa de este apartado sobre la escatología es cómo el Señor es fuente de vida, y esa vida no es otra que la vida en el Padre como hijos ${ }^{135}$.

\section{5. PÁRRAFO QUINTO: La vocación divina de todo hombre}

"Esto vale no solamente para los cristianos, sino también para todos los hombres de buena voluntad, en cuyo corazón obra la gracia de modo invisible. Cristo murió por todos, y la vocación suprema del hombre en realidad es una sola, es decir, la divina. En consecuencia, debemos creer que el Espíritu Santo ofrece a todos la posibilidad de que, en la forma de sólo Dios conocida, se asocien a este misterio pascual".

La primera afirmación de este párrafo nos habla de la universalidad de la redención de Cristo: "Cristo murió por todos" 136 Esta afirmación se ve respaldada con la cita de Rom 8,32, que nos indica el gran amor que tiene el Padre por los hombres, que nos entrega a su Hijo y nos da la vida. Ese todos, son todos los "hombres de buena voluntad, en cuyo corazón obra la gracia de modo invisible", remitiéndose la Constitución pastoral a Lumen Gentium 16.

En la participación del misterio pascual de Jesús, el Espíritu Santo ofrece a todos la posibilidad de que en el modo como Dios conoce vengan asociados todos los hombres al misterio pascual. Se subraya con todo esto la universalidad de la redención de Cristo ${ }^{137}$.

134. Cf. H. DE LuBAC, Ateísmo y sentido del hombre, ed.c., 66.

135. Cf. J. GALOT, "Cristo revelador, fundador de la Iglesia y principio de vida", en R. LATOURELLE (ed.), o.c., 272.

136. "Aquí es donde el concilio afirma con la mayor energía que el estado del hombre renovado según Cristo no es monopolio de los cristianos". E. SCHILLEBEECKX, "Fe cristiana y espera temporal", en AA. VV., La Iglesia en el mundo actual, Bilbao 1968, 124.

137. Cf. L. F. LADARIA, "El hombre a la luz de Cristo en el concilio Vaticano II", en R. LATOURELLE (ed.), o.c., 709 . 
La segunda afirmación de este párrafo es "la vocación suprema del hombre (...) la divina", la vocación divina del hombre es revelada plenamente en Cristo ${ }^{138}$. El Hijo "...hace de todos los hombres, en potencia y desde la vocación, hijos de Dios"139. Nadie está excluido de esta vocación, sin embargo el concilio no se mete en el cómo ${ }^{140}$. Todo hombre está llamado a salvarse y a participar en la vida de Jesús resucitado. El Espíritu Santo es el que ofrece a todos esa posibilidad. Con este párrafo se ha recuperado una antigua tradición teológica que afirmaba la universalidad de la gracia ${ }^{141}$.

\section{6. PÁRRAFO SEXTO: "Hijos en el Hijo, clamamos en el Espíritu: Abba!"}

"Este el gran misterio del hombre que la Revelación cristiana esclarece a los fieles. Por Cristo y en Cristo se ilumina el enigma del dolor y de la muerte, que fuera del Evangelio nos envuelve en absoluta oscuridad. Cristo resucitó; con su muerte destruyó la muerte y nos dio la vida, para que hijos en el Hijo, clamamos en el Espíritu: Abba!, ¡Padre!".

La conclusión de este número 22 es una síntesis de lo desarrollado anteriormente, y una confirmación a la respuesta sobre la muerte expuesta en GS 18b. El Hijo que entra en la historia del hombre, se revela a sí mismo y revela a la vez el misterio del hombre. Contesta la pregunta sobre el sentido de la vida humana, responde a esa "semilla de eternidad que en sí lleva" (GS 18), e

138. K. Wojtyla escribirá pocos años después del concilio, uniendo la pregunta qué es el hombre a su voćación: "La revelación del misterio del Padre y de su amor en Jesucristo revela el hombre al hombre, con la respuesta última a la pregunta de ¿qué es el hombre?. No podemos separar esta respuesta del problema de su vocación; el hombre manifiesta lo que es aceptando su propia vocación y realizándola". K. WoJTYLA, La renovación en sus fuentes, Madrid 1982, 60. Por su parte L. F. Ladaria afirmará:" No podemos saber plenamente lo que es el hombre, lo que estamos llamados a ser nosotros, si no ponemos en Cristo nuestra mirada. La única vocación del hombre es la divina, porque desde siempre ha sido pensado para ser miembro del cuerpo de Cristo y para reproducir su imagen." L. F. LADARIA, "El hombre, imagen de Dios", en Miscelánea Comillas 43 (1985) 397.

139. J. Mouroux, "Sobre la dignidad de la persona humana", en Y. M.-J. CongAR - M. Peuchmaurd (dirs.), o.c. II, 309.

140. L.F. Ladaria recuerda los problemas que en aquel tiempo no estaban resueltos del todo (relación naturaleza-gracia, los motivos de la encarnación), y que explican que el concilio no tomase una posición. Cf. L.F. LADARIA, El hombre como tema teológico, ed.c., 32-33.

141. Para un mayor estudio del tema puede verse a J. I. GonZÁlez FAUS, Proyecto de hermano, ed.c., 475-478. 
ilumina el enigma del dolor y la muerte. Porque la muerte de Cristo destruye nuestra muerte, ante la cual "toda imaginación fracasa" (GS 18b). Sólo la revelación cristiana nos proporciona esa luz, y esa esperanza. Por la resurrección del Hijo los hombres recibimos la vida, somos adoptados como hijos en el Hijo, que con su muerte nos ha ganado para Dios. Como dice L.F. Ladaria: "El hombre alcanza su plenitud cuando, en virtud de la acción del Espíritu, es hijo en el Hijo, participa de la relación irrepetible que Jesús tiene con el Padre" 142 .

La dimensión trinitaria de la salvación se plantea como algo esencial, el hombre se siente llamado a participar de la comunión trinitaria, es su vocación, es el volver la vista y ansiar el encuentro con la fuente de la vida. El papel redentor del Hijo, que nos envía el Espíritu nos proporciona una vida nueva en la que podemos dirigirnos, en el Espíritu, al Padre como hijos, llamándole $A b b a$ !, y participar, por tanto, de la relación de filiación de Cristo, con el Padre, en el Espíritu Santo.

\section{CONCLUSIÓN}

La constitución pastoral vuelve sus ojos a Dios y fundamenta en Él la dignidad del hombre, que ha sido creado a su imagen. El hombre constantemente se pregunta por su destino, y se cuestiona por el sentido de la propia existencia: ¿de dónde vengo?, ¿a dónde voy?, ¿quién soy?. Para la constitución pastoral la respuesta tiene que ver con la vocación del hombre, de todo hombre y de todos los hombres, que es Dios mismo. La llamada a estar en su seno, a la felicidad completa que sólo Él puede ofrecer al hombre. El deseo de lo absoluto, que nace de lo profundo del hombre, sólo lo puede llenar Dios, porque es el origen y meta del hombre, con palabras de S. Agustín que recoge el Concilio: «nos hiciste Señor para ti y nuestro corazón está inquieto hasta que descanse en ti» (GS 21g)

Tres números se pueden considerar que son claves el 12,13, y 22, dado que en ellos se desarrolla toda la antropología cristiana. EI hombre creado a imagen de Dios, cae en el pecado, y es salvado por Jesús que sitúa al hombre

142. L. F. LADARIA, "El hombre a la luz de Cristo en el concilio Vaticano II", en R. LATOURELle (ed.), o.c., 709. 
en un estado nuevo: el de hijos. El hombre creado a imagen de Dios se relaciona con Dios de una forma única, es el interlocutor válido del Creador, es su imagen, en el que Dios se ve reflejado, y en ello radica su dignidad. Creado a imagen de Dios es constituido señor y dueño de la creación, es responsable de su cuidado, y de transformarla cooperando en la acción creadora de Dios. Está por tanto, sobre todo lo material, es sujeto, no objeto, y como tal debe tratarse y comportarse.

La Constitución, sin embargo, no olvida la tragedia del hombre, el hecho de que el hombre "creado por Dios en la justicia, (...) abusó de su libertad levantándose contra Dios y pretendiendo alcanzar su propio fin al margen de Dios" (GS 13). El hombre es pecador, en el interior del corazón humano late un deseo de ser como Dios, pero sin Dios. El hombre se alza soberbio y egoísta contra Dios y sus hermanos, se recluye en sí mismo, alza ídolos y les sacrifica su propia vida. El pecado personal, social y estructural tiene su raíz en este primer pecado propio del ser del hombre, que creado libre por Dios, también es capaz de rechazar el amor de Dios, y su infinita misericordia. La consecuencia más inmediata es la muerte, la disolución del ser, que plantea en su dramatismo la posibilidad de una muerte definitiva, si el hombre rechaza al que es la Vida. Por su parte, el número 22 es un texto clave que recoge lo anterior, y que plantea el núcleo de la soteriología y antropología cristiana. Juan Pablo II lo ha indicado constantemente citando la frase más significativa de este número: " el misterio del hombre sólo se esclarece en el misterio del Verbo encarnado" (Redemptor Hominis, 8). El Hijo se ha encarnado, se ha hecho uno de nosotros, ha trabajado, y ha compartido la vida social propia de su tiempo. Nos ha revelado definitivamente al Padre y el amor del Espíritu Santo, y no sólo nos ha salvado, sino que nos ha otorgado como don el ser hijos de Dios, porque “...Cristo resucitó; con su muerte destruyó la muerte y nos dio la vida, para que hijos en el Hijo, clamemos en el Espíritu: $A b b a !$, ¡Padre!” (GS 22f).

La centralidad de Cristo en todo el texto conciliar es patente. Tal y como veíamos en el tercer apartado, los capítulos de la primera parte suelen acabar con un numero cristológico, y en la segunda no falta su mención. Sin embargo no vemos un cristomonismo, sino a Cristo que nos revela al Padre y al Espíritu Santo. Cristo que en su encarnación nos dice que es posible esa unión entre lo humano y lo divino, gracias al amor de Dios, y que nos revela al hombre lo que es, el propio hombre: hijo y hermano. Cristo, es el hombre nuevo, es el modelo antropológico por excelencia.

Desde la constitución pastoral podemos definir al hombre como ser subsistente, consciente de quien es, y abierto a Dios y los otros, a imagen de Dios trino, o sea como "comunión-solidaridad". El hombre a imagen de Dios trini- 
tario, constituido en hijo y hermano, y colaborador de la obra creadora de Dios vive en la historia esperando el fin de los tiempos, el fin último que coincide con el origen primero: Dios. La vocación del hombre de ser-en Dios implica actuar con el mismo amor que nos tiene el Padre, configurarse con Cristo implica amar como Él amó, hasta dar la vida. El Espíritu mantiene la esperanza, da la vida, alienta el ser del hombre, y guía la historia humana hacia su consumación.

Fernando Bogónez Herreras

Estudio Teológico Agustiniano

VALLADOLID 